\title{
Carolina Bori
}

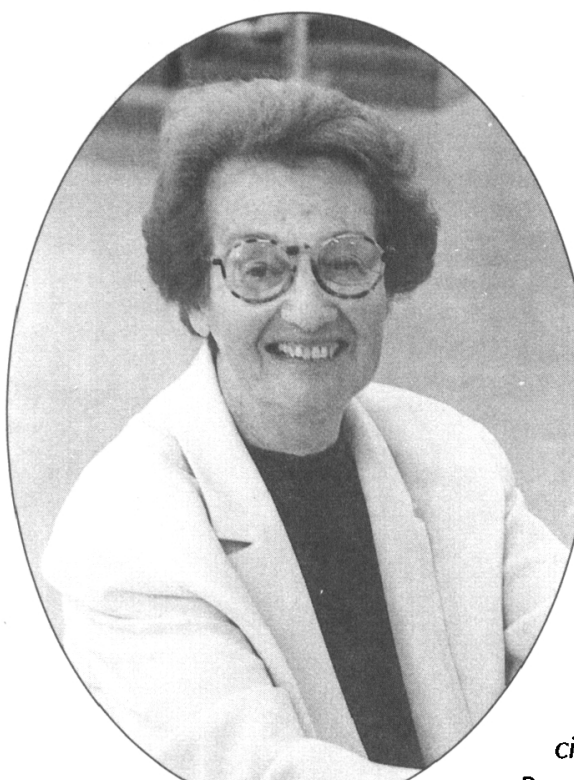

Brasileira de Psicologia e a Associação Nacional de Pesquisa e PósGraduação em Psicologia - Anpepp. Contribuiu também para o comprometimento da comunidade acadêmica com as grandes questões políticas e sociais de uma fase especialmente conturbada da vida nacional. A extinção do $\mathrm{Al}-5$, a defesa dos direitos humanos, a liberdade de reunião e de expressão e a luta contra o programa nuclear foram apenas algumas das bandeiras que a comunidade científica brasileira levantou nas últimas décadas, sempre com a participação ativa de Carolina Bori.

O resumo do currículo de Carolina Bori pode dar uma idéia da diversidade e a abrangência de sua atuação, bem como da constância e da intensidade de sua participação na vida acadêmica brasileira. Além disso, ela também tem importantes participações em conselhos editoriais de diversas publicações. Algumas de suas atividades foram:

- 1952, Master of Arts pela Graduate School of the New School for Social Research.

- 1954, Doutora em Psicologia pela USP.

- 1954-1955 e 1963-1965, Presidente da Associação Brasileira de Psicologia.

- 1959, Professora de Psicologia da Faculdade de Filosofia, Ciências e Letras de Rio Claro (SP).

- 1960-1961, Presidente da Sociedade de Psicologia de São Paulo.

- 1963-1965, Organizadora e Chefe do Departamento de Psicologia da UnB.

- 1966, Research Associate, Institute of Latin American Research, University of Texas.

- 1968-1969, Chefe do Departamento de Psicologia Social e Experimental da USP.

- 1969-1971, Chefe do Departamento de Psicologia Experimental da USP.

- 1970-1984, Presidente da Comissão de Pós-Graduação em Psicologia do Instituto de Psicologia da USP.

- 1973-1977, Primeira Secretária da SBPC.

- 1976, Membro do Crupo de Trabalho responsável pela organização da Associação de Doçentes da USP.

- 1976-1979, Diretora do Centro de Educação e Ciências Humanas da Universidade Federal de São Carlos.

- 1977-1981, Secretária Geral da SBPC.

- 1981-1986, Vice-Presidente da SBPC.

- 1982-1984, Membro do Comitê Assessor em Ciências Humanas e Sociais do CNPQ.

- Desde 1984, Coordenadora no Núcleo de Documentação sobre Formação Científica do Instituto Brasileiro de Educação, Cultura e Ciência (IBECC).

- Desde 1997, Membro da Comissão de Especialistas em Psicologia do MEC.

- 1984-1986, Presidente da Anpepp.

- 1985-1987, Presidente de Área da Comissão de Acompanhamento e Avaliação de Cursos de Pós-Graduação do Capes/MEC.

- 1986-1989, Presidente da SBPC.

- Desde 1989, Presidente de Honra da SBPC.

- 1990-1994, Coordenadora do Projeto "Estação Ciência", USP/CNPQ

- 1992-1993, Presidente da Sociedade Brasileira de Psicologia.

- Desde 1993, Diretora Científica do IBECC-Comissão de São Paulo.

- Desde 1994, Professora Emérito do Instituto de Psicologia da USP e Membro do Conselho Diretor da Fundação

"Universidade de Brasília".

-1995-1996, Presidente da Comissão de Especialistas de Psicologia do MEC.

- Desde 1996, Diretora Científica do Núcleo de Pesquisa sobre Ensino Superior da USP (NUPES).
Colaboração: Ana Maria Almeida Carvalho Maria Amelia Matos Eda T. de Oliveira Tassara Maria Ignez Rocha e Silva Deisy das Graças de Souza 